\title{
Effect of renal clearance and continuous renal replacement therapy on appropriateness of recommended meropenem dosing regimens in critically ill patients with susceptible life-threatening infections
}

\author{
Raphaël Burger ${ }^{1,2 *}+$, Monia Guidi ${ }^{3,4}+$, Valérie Calpini ${ }^{4}$, Frédéric Lamoth ${ }^{2,5}$, Laurent Decosterd ${ }^{3}$, Corinne Robatel ${ }^{3}$, \\ Thierry Buclin ${ }^{3}$, Chantal Csajka ${ }^{3,4} \neq$ and Oscar Marchetti ${ }^{2,6} \neq$ \\ ${ }^{1}$ Internal Medicine Service, Department of Medicine, Lausanne University Hospital (CHUV), Lausanne, Switzerland; ${ }^{2}$ Infectious Diseases \\ Service, Department of Medicine, Lausanne University Hospital (CHUV), Lausanne, Switzerland; ${ }^{3}$ Clinical Pharmacology Service, \\ Lausanne University Hospital (CHUV), Lausanne, Switzerland; ${ }^{4}$ School of Pharmaceutical Sciences, University of Geneva, University of \\ Lausanne, Geneva, Switzerland; ${ }^{5}$ Institute of Microbiology, Department of Laboratories, Lausanne University Hospital (CHUV), \\ Lausanne, Switzerland; ${ }^{6}$ Department of Medicine, Ensemble Hospitalier de la Côte, Morges, Switzerland
}
${ }^{*}$ Corresponding author. Service de Médecine Interne, Département de Médecine, Centre Hospitalier Universitaire Vaudois (CHUV), Rue du Bugnon 46, 1011 Lausanne, Switzerland. Tel: +41 7955638 27; E-mail: raphael.burger@chuv.ch †Contributed equally as first authors. ‡Contributed equally as senior authors.

Received 1 April 2018; returned 8 June 2018; revised 6 August 2018; accepted 20 August 2018

Background: Meropenem plasma concentration above a pathogen's MIC over the whole dosing interval (100\% $\left.f T_{>\text {MIC }}\right)$ is a determinant of outcome in severe infections. Significant variability of meropenem pharmacokinetics is reported in ICU patients.

Objectives: To characterize meropenem pharmacokinetics in variable $\mathrm{CL}_{\mathrm{CR}}$ or renal replacement therapy and assess the appropriateness of recommended regimens for MIC coverage.

\begin{abstract}
Methods: A pharmacokinetic analysis (NONMEM) was conducted with external model validation. Patient characteristics were tested on meropenem clearance estimates, differentiated according to the presence/absence of continuous renal replacement therapy (CRRT, $\mathrm{CL}_{\text {CRRT }}$ or $\mathrm{CL}_{\text {no-CRRT }}$ ). Simulations evaluated the appropriateness of recommended dosing for achieving $100 \%$ fT $>$ MIC in $90 \%$ of patients.
\end{abstract}

Results: A total of 101 patients were studied: median 63 years (range 49-70), 56\% male, SAPS II 38 (27-48). $32 \%$ had a $\mathrm{CL}_{\mathrm{CR}}>60 \mathrm{~mL} / \mathrm{min}, 49 \%$ underwent CRRT and $32 \%$ presented severe sepsis or septic shock. A total of 127 pathogens were documented: $76 \%$ Gram-negatives, $24 \%$ Gram-positives (meropenem MIC 902 mg/L, corresponding to EUCAST susceptibility breakpoint). Three hundred and eighty plasma and 129 filtrate-dialysate meropenem concentrations were analysed: two-compartment modelling best described the data. Predicted meropenem $\mathrm{CL}_{\text {no-CRRT }}$ was $59 \%$ lower in impaired $\left(\mathrm{CL}_{\mathrm{CR}} 30 \mathrm{~mL} / \mathrm{min}\right.$ ) compared to normal $\left(\mathrm{CL}_{C R} 100 \mathrm{~mL} / \mathrm{min}\right.$ ) renal function. Simulations showed that recommended regimens appropriately cover $\mathrm{MIC}_{90}$ in patients with $\mathrm{CL}_{C R}$ $<60 \mathrm{~mL} / \mathrm{min}$. Patients with $\mathrm{CL}_{\mathrm{CR}}$ of 60 to $<90 \mathrm{~mL} /$ min need $6 \mathrm{~g} /$ day to achieve appropriate coverage. In patients with $\mathrm{CL}_{\mathrm{CR}} \geq 90 \mathrm{~mL} / \mathrm{min}$, appropriate exposure is achieved with increased dose, frequency of administration and infusion duration, or continuous infusion.

Conclusions: Recommended meropenem regimens are suboptimal in ICU patients with normal or augmented renal clearance. Modified dosing or infusion modalities achieve appropriate MIC coverage for optimized antibacterial efficacy in meropenem-susceptible life-threatening infections.

\section{Introduction}

Sepsis is a leading cause of death in critically ill patients despite prompt administration of an appropriate antimicrobial therapy at recommended dosing regimens. ${ }^{1-4}$ Standard drug dosing may not be suited to the specific pharmacokinetic (PK) characteristics of this patient population. ${ }^{5-8}$ Altered fluid status, microvascular failure and rapid changes in renal and hepatic function significantly modify drug PK. Insufficient antibiotic exposure, particularly for 
microorganisms with reduced susceptibility, may be associated with treatment failure. ${ }^{9}$

Meropenem is a broad-spectrum $\beta$-lactam antibiotic of the carbapenem class. Unlike imipenem, meropenem is relatively stable in plasma, and does not require combination with a dehydropeptidase-1 inhibitor; however, meropenem has a short half-life of $\sim 1 \mathrm{~h}$. Two percent of the drug is bound to plasma proteins and $98 \%$ is free circulating as microbiologically active fraction. Elimination is mainly renal through glomerular filtration and tubular secretion, with $60 \%-80 \%$ of the dose being recovered unaltered in the urine, $2 \%$ in the faeces and the remaining fraction being eliminated as inactive metabolite. ${ }^{10-12}$ In renal failure, the half-life of meropenem is increased up to 10 -fold. In continuous renal replacement therapy (CRRT), the half-life is $\sim 4.5 \mathrm{~h}$, drug clearance being determined by the volume of filtrate produced and the dialysate flow rate. ${ }^{13,14}$

The best pharmacodynamic (PD) predictor of microbiological efficacy of $\beta$-lactam antibiotics is the percentage of the time interval ( $T$ ) between two administrations during which the plasma concentration of the unbound drug fraction $(f)$ exceeds the MIC for the causative pathogen (\% fT $>$ MIC). In vitro and animal studies have shown a maximum killing rate at $40 \% f T_{>\text {MIC }}$ for carbapenems, whereas $60 \%-70 \%$ and $50 \%$ are required for penicillins and cephalosporins, respectively. ${ }^{15,16}$ Clinical studies suggest that a higher exposure is required for efficacy, in particular in patients with severe infections. ${ }^{17,18}$ Recently, an association between favourable clinical outcome and $100 \% f T_{>\text {MIC }}$ was reported in critically ill patients. ${ }^{9}$ Additionally, a more aggressive target of $100 \%$ $f T_{>4 \times \text { MIC }}$ has been proposed to suppress the emergence of resistance, with uncertain impact on individual clinical outcomes. ${ }^{19}$ Whether these targets can be achieved with recommended meropenem dosing regimens remains uncertain, particularly in patients with infections due to pathogens with higher MICs such as Pseudomonas aeruginosa or Acinetobacter baumannii. In critically ill patients with sepsis, burns or poly-trauma, augmented renal clearance (ARC) predicted subtherapeutic $\beta$-lactam concentrations. ${ }^{7,19-23}$ Whereas dose adjustment is routinely recommended in patients with impaired renal function, the dose increase in patients with ARC is not standard practice. ${ }^{24}$

We performed a population PK analysis to characterize the PK profile of meropenem in critically ill patients in variable renal function or renal replacement therapy and assessed the appropriateness of recommended dosing regimens for MIC coverage in ICU patients with life-threatening infections through simulations.

\section{Materials and methods}

\section{Study design and population}

This study was performed in a 35-bed tertiary medico-surgical ICU at the Lausanne University Hospital. Ethics approval was obtained from the institutional ethics committee on human research (protocol no. 109/08).

Eighty-six adult patients admitted to the ICU from October 2010 to March 2013 and receiving meropenem treatment were either prospectively enrolled in a therapeutic drug monitoring (TDM) study, which aimed to assess the clinical utility of measuring antibiotic blood concentrations $(n=30)$ or were included in the institutional TDM programme, which aimed to individualize drug dosing according to blood concentrations and clinical plus microbiological characteristics $(n=56)$. In both settings, clinical, laboratory and pharmacological data were collected from the electronic health records. In addition, data from 15 patients enrolled in a previous study by Robatel et al. $^{14}$ on continuous veno-venous haemodiafiltration (CVVHDF) with rich meropenem plasma and filtrate-dialysate fluid samplings were included in the analysis $(n=101)$. An independent dataset from 43 individuals undergoing meropenem TDM between April and September 2013 was used for external model validation.

Clinical and laboratory data included age, gender, body weight, serum creatinine, SAPS II and APACHE II scores, ${ }^{25,26}$ hospital and ICU length of stay, and overall survival. Data on clinical and microbiological documentation of infection as well as severity at presentation were collected. Pharmacological data included meropenem dosing schedule, timing, infusion time, use of CRRT, i.e. haemofiltration or haemodiafiltration, with predilution, post-dilution and effluent flow rates. $\mathrm{CL}_{\mathrm{CR}_{\mathrm{R}}}$ was calculated with the Cockcroft-Gault equation. ${ }^{27}$ ARC was defined as $\mathrm{CL}_{\mathrm{CR}}$ between 130 and $160 \mathrm{~mL} / \mathrm{min}$. CRRT was performed using $1.2 \mathrm{~m}^{2}$ filters (Aquarius system with Aquamax Hemofilter; Baxter, USA). Filter flow rate was calculated as the sum of pre-dilution, post-dilution and effluent flow rates.

Infectious episodes were categorized according to the modified definitions from the International Immunocompromised Host Society: microbiologically documented infection with or without bacteraemia, clinically documented infection, or fever of unknown origin. ${ }^{28}$ The sites of infection were characterized based on the clinical and microbiological documentation. The severity of infection was classified according to international definitions. $^{29}$

Microbiological data for pathogens documented in cultures included species identification and MIC of meropenem. EUCAST epidemiological MIC cut-off values were used for analysis in the absence of a quantified MIC. $\mathrm{MIC}_{50}$ and $\mathrm{MIC}_{90}$ of the isolated microorganisms were calculated. Two mg/L is the clinical MIC breakpoint for meropenem susceptibility in the majority of bacteria according to EUCAST. ${ }^{30}$

\section{Sample collection and analysis}

For patients participating in the prospective study or from the TDM programme, $3 \mathrm{~mL}$ venous blood samples were collected at steady-state, i.e. after a minimum of three identical doses, usually 2-4 days after initiating meropenem therapy and after a change in meropenem dosage. The 30 patients included in the prospective study had samples drawn at peak ( $1 \mathrm{~h}$ ) and trough ( $8-12 \mathrm{~h}$ ) hours after drug administration, depending on the meropenem regimen used. The patients from the TDM programme had samples drawn at trough. The blood collection procedure at serial timepoints during the dosing interval in 15 patients from the Robatel et al. ${ }^{14}$ study is described in that publication. Data on plasma and filtrate-dialysate meropenem concentrations in 15 patients from Robatel et al. ${ }^{14,31}$ were extracted from the study database.

Blood samples were collected in citrated tubes and immediately stored at $4^{\circ} \mathrm{C}$ in the hospitalization unit. The samples were centrifuged within 1 hour and frozen at $-80^{\circ} \mathrm{C}$. Meropenem plasma concentrations were quantified by UPLC-MS for the prospective study and the TDM programme or by HPLCUV for the Robatel et al. ${ }^{14}$ study. Both methods were validated according to international analytical standards ( $\pm 15 \%$ inaccuracy and precision) as recommended by the FDA and the Conference Report of the Washington Conference on 'Analytical Methods Validation: Bioavailability, Bioequivalence and Pharmacokinetic Studies' and the Arlington Workshop. ${ }^{32-36}$ An internal cross-validation showed a concordance of meropenem concentrations (accuracy $\pm 95 \%$ ) measured with the two analytical methods.

\section{PK analysis}

Data analysis was performed using the non-linear mixed effect modelling program NONMEM ${ }^{\circledR}$ ver. $7.2^{37}$ with the PSN-toolkit v. 3.5.3 and Xpose4. ${ }^{38-41}$ A stepwise procedure was undertaken to determine the model that best 
Table 1. Recommended meropenem dosing regimens according to creatinine clearance

\begin{tabular}{|c|c|c|c|c|c|}
\hline & \multicolumn{4}{|c|}{ Creatinine clearance $(\mathrm{mL} / \mathrm{min})$} & \multirow[b]{2}{*}{$\mathrm{CRRT}^{14}$} \\
\hline & $>90$ & 60 to $<90$ & 30 to $<60$ & 15 to $<30$ & \\
\hline Standard dosing ${ }^{a}$ & $1000 \mathrm{mg} \mathrm{q} 8 \mathrm{~h}$ & $1000 \mathrm{mg} \mathrm{q} 8 \mathrm{~h}$ & $1000 \mathrm{mg} \mathrm{q} 12 \mathrm{~h}$ & $500 \mathrm{mg} \mathrm{q} 8 \mathrm{~h}$ & $1000 \mathrm{mg} \mathrm{q} 12 \mathrm{~h}$ \\
\hline Dosing in severe infections & $2000 \mathrm{mg}$ q8h & $2000 \mathrm{mg} \mathrm{q} 8 \mathrm{~h}$ & $2000 \mathrm{mg} \mathrm{q12h}$ & $1500 \mathrm{mg} \mathrm{q} 12 \mathrm{~h}$ & $1500 \mathrm{mg} \mathrm{q} 12 \mathrm{~h}$ \\
\hline
\end{tabular}

aManufacturer's recommendations. ${ }^{12}$

fitted the data. Graphical exploration, figures generation and statistical analyses were performed using the R package v. 2.15 .1 (http://www.r-pro ject.org/) and STATA ${ }^{\circledR}$ V.13 (StataCorp LP).

\section{Base model}

Model development was first conducted on the rich plasma and filtrate-dialysate data collected in 15 patients of the Robatel et al. ${ }^{14}$ study. Multicompartment models with linear elimination were compared to describe plasma concentration-time profiles. Distinct meropenem clearance was assumed for patients undergoing CRRT versus those with spontaneous renal clearance $\left(\mathrm{CL}_{\mathrm{CRRT}}\right.$ or $\left.\mathrm{CL}_{\text {no-CRRT }}\right)$. Meropenem extracorporeal clearance due to CVVHDF was directly integrated in the model using the relationship $\mathrm{CL}_{\mathrm{CRRT}}=S_{\mathrm{C}} \cdot Q_{\mathrm{FD}}$, where $S_{\mathrm{C}}$ is the sieving coefficient, defined as the ratio between plasma and filtrate-dialysate concentrations, and $Q_{\mathrm{FD}}$ the filtrate-dialysate flow. A residual $\mathrm{CL}\left(\mathrm{CL}_{\text {res }}\right)$ was estimated to account for the nonrenal elimination of meropenem. Total meropenem clearance in patients undergoing CRRT was assumed to be the sum of $\mathrm{CL}_{\mathrm{CRRT}}+\mathrm{CL}_{\text {res }}$. Estimated parameters were drug clearances $\left(\mathrm{CL}_{\text {no-CRRT }}, \mathrm{CL}_{\text {res }}\right)$, volumes of distribution as well as $S_{c}$. Between-subject variability was described by exponential errors following a log-normal distribution. Proportional, additive and mixed proportional-additive error models were compared to describe residual variability in plasma and filtrate-dialysate fluid.

The obtained base model was extended and refined on the complete model-building dataset, distinguishing patients undergoing CRRT. Distinct intra-individual variabilities were associated with rich, TDM study and routine TDM data. We assumed a similar $S_{c}$ for $C V V H$ and CVVHDF as a negligible difference of meropenem extraction has been found between the two methods. ${ }^{42}$

\section{Covariate analysis}

Visual inspection of the relationships between individual Bayesian parameter estimates and the covariates was carried out first. Sequential forward insertion followed by backward deletion was then conducted for covariate testing using linear or non-linear functions (continuous covariates centred on the population median; dichotomous variables coded as $0 / 1$ ). Missing values were imputed to the median population value for continuous covariates. Baseline characteristics evaluated for their impact on meropenem PK were gender, age, body weight and $\mathrm{CL}_{\mathrm{CR}}$.

\section{Parameter estimation and model selection}

The data were fitted using the first-order conditional estimation method with interaction. Difference in NONMEM ${ }^{\circledR}$ objective function value $(\triangle \mathrm{OFV})$, along with diagnostic goodness-of-fit plots, were employed to discriminate between hierarchical models (as $\triangle \mathrm{OFV}$ for nested models approximates a $\chi^{2}$ distribution). A $3.8(P=0.05)$ and $6.6(P=0.01)$ point change for one additional parameter for forward insertion and backward deletion procedures, respectively, was considered statistically significant.

\section{Model validation}

The final model stability was assessed by the bootstrap method, computing 2000 replicates of the original dataset. ${ }^{38,39}$ The derived median parameter values with their CIs (95\% CI) were compared with original estimates. Prediction-corrected visual predictive checks ( $p c V P C)$ were performed by simulations based on the final PK model with variability using 1000 individuals to calculate median and $90 \%$ prediction intervals with their 95\% CI. ${ }^{38-41}$ Finally, population and individual post hoc concentrations derived from applying the final PK model on the external model validation dataset were analysed to assess model accuracy by mean prediction error. ${ }^{43,44}$

\section{Dosing regimen simulations}

Monte Carlo simulations based on the final model with variability were undertaken to assess the adequacy of different meropenem dosing regimens. One thousand $70 \mathrm{~kg}$ individuals were simulated for each regimen assuming uniformly distributed $Q_{F D}$ or $\mathrm{CL}_{\mathrm{CR}}$ over the range of interest (i.e. $Q_{\mathrm{FD}}: 1000$ to $<2000 \mathrm{~mL} / \mathrm{h}$ or 2000 to $<3000 \mathrm{~mL} / \mathrm{h} ; \mathrm{CL}_{\mathrm{CR}}: 15$ to $<30,30$ to $<60,60$ to $<90,90$ to $<130$ or $130-160 \mathrm{~mL} / \mathrm{min}$ ) for patients with and without CRRT, respectively. Analysed meropenem dosing regimens included $0.5,1$ and $2 \mathrm{~g}$ q12h and q8h as well as $1.5 \mathrm{~g}$ q12h with 30 min infusion for subjects undergoing CRRT or with impaired renal function $\left(\mathrm{CL}_{\mathrm{CR}}<60 \mathrm{~mL}\right.$ / $\mathrm{min}$ ). These meropenem dosing regimens were based on manufacturer and hospital recommendations (Table 1). Meropenem infusions $>30$ and $120 \mathrm{~min}$ for six dosing regimens $(0.75 / 1.5 \mathrm{~g} q 6 \mathrm{~h}, 0.5 / 1 \mathrm{~g} q 4 \mathrm{~h}$ and $1 / 2 \mathrm{~g} q 8 \mathrm{~h})$ were simulated for normal clearance $\left(60 \mathrm{~mL} / \mathrm{min}<\mathrm{CL}_{\mathrm{CR}}<130 \mathrm{~mL} / \mathrm{min}\right)$ and ARC. Finally, the performance of continuous meropenem infusions using the same total daily dose as in the above regimens was simulated for comparison. The PTA was calculated over a range of doubling MICs from 0.125 to $64 \mathrm{mg} / \mathrm{L}$ with a target of $100 \% f T_{>\text {MIC }}$. Regimens with PTAs $>90 \%$ were considered appropriate.

\section{Results}

Model development was performed on 380 meropenem plasma concentrations in 101 ICU patients (median per patient 2, range 120), in addition to 129 filtrate-dialysate samples (9, 7-10). Eighty plasma concentrations from 43 patients $(1,1-8)$ were analysed for model validation. Patient characteristics in model building and external validation datasets are shown in Table 2. Forty-nine percent of patients underwent CRRT, $32 \%$ of the remaining cases had a $\mathrm{CL}_{\mathrm{CR}}>60 \mathrm{~mL} / \mathrm{min}$.

One hundred and twenty-seven meropenem-susceptible pathogens were documented with an $\mathrm{MIC}_{50}$ of $0.125 \mathrm{mg} / \mathrm{L}$ (IQR $0.125-0.5 \mathrm{mg} / \mathrm{L}$ ) and an $\mathrm{MIC}_{90}$ of $2 \mathrm{mg} / \mathrm{L}$ (Table 3). P. aeruginosa was isolated in 20 (15.7\%) microbiologically documented infections. 
Table 2. Patient demographics and clinical characteristics

\begin{tabular}{|c|c|c|}
\hline Characteristics & $\begin{array}{l}\text { Model building } \\
\quad(n=101)\end{array}$ & $\begin{array}{c}\text { External } \\
\text { validation } \\
(n=43)\end{array}$ \\
\hline Age, years & $63(49-70)$ & $62(50-69)$ \\
\hline Male, $n(\%)$ & $57(56)$ & $30(70)$ \\
\hline Body weight, kg & $72(58-85)$ & $74(64-87)$ \\
\hline APACHE score, ${ }^{a}$ points & $22(17-25)$ & $22(18-26)$ \\
\hline SAPS II score, ${ }^{a}$ points & $38(27-48)$ & $38(26-48)$ \\
\hline \multicolumn{3}{|l|}{ Calculated $\mathrm{CL}_{\mathrm{CR}}{ }^{\mathrm{b}, \mathrm{c}} \mathrm{n}(\%)$} \\
\hline$>130 \mathrm{~mL} / \mathrm{min}$ (ARC) & $11(11)$ & $9(21)$ \\
\hline $90-129 \mathrm{~mL} / \mathrm{min}$ & $7(7)$ & $10(23)$ \\
\hline 60 to $<90 \mathrm{~mL} / \mathrm{min}$ & $14(14)$ & $6(14)$ \\
\hline 30 to $<60 \mathrm{~mL} / \mathrm{min}$ & $17(17)$ & $5(12)$ \\
\hline 15 to $<30 \mathrm{~mL} / \mathrm{min}$ & $7(7)$ & $3(7)$ \\
\hline$<15 \mathrm{~mL} / \mathrm{min}$ & $1(1)$ & $1(2)$ \\
\hline CRRT,,${ }^{c, d} n(\%)$ & $49(49)$ & $12(28)$ \\
\hline ICU LOS, ${ }^{a}$ days & $22(10-34)$ & $17(9-29)$ \\
\hline Hospital LOS, ${ }^{a}$ days & $44(28-78)$ & $38(25-77)$ \\
\hline Duration of antibiotic therapy, ${ }^{\mathrm{a}, \mathrm{e}}$ days & $9(6-14)$ & $8(5-14)$ \\
\hline \multicolumn{3}{|l|}{ Classification of infection, ${ }^{\mathrm{a}, \mathrm{e}} \mathrm{n}(\%)$} \\
\hline MDI-B & $33(33.7)$ & $16(32.0)$ \\
\hline MDI-NB & $34(34.7)$ & $22(44.0)$ \\
\hline CDI & $9(9.2)$ & $10(20.0)$ \\
\hline FUO & $22(22.5)$ & $2(4.0)$ \\
\hline \multicolumn{3}{|l|}{ Severity of infection, ${ }^{\mathrm{a}, \mathrm{e}} \mathrm{n}(\%)$} \\
\hline sepsis & $48(49.0)$ & $26(52.0)$ \\
\hline septic shock & $31(31.6)$ & $16(32.0)$ \\
\hline multi-organ failure & $7(7.1)$ & $1(2.0)$ \\
\hline \multicolumn{3}{|l|}{ Site of infection, ${ }^{\mathrm{a}, \mathrm{e}} \mathrm{n}(\%)$} \\
\hline pneumonia & $40(40.8)$ & $27(54)$ \\
\hline vascular catheter-related bacteraemia & $12(12.2)$ & $5(10)$ \\
\hline cellulitis & $12(12.2)$ & $2(4)$ \\
\hline peritonitis & $9(9.1)$ & $5(10)$ \\
\hline other & $3(3.1)$ & $9(18)$ \\
\hline unknown origin & $22(22.5)$ & $2(4)$ \\
\hline Deaths, $n(\%)$ & $39(39)$ & $17(40)$ \\
\hline
\end{tabular}

Data are presented as median (IQR) or number (\%).

APACHE, Acute Physiology and Chronic Health Evaluation; SAPS II, Simplified Acute Physiology Score II; LOS, length of stay; MDI, microbiologically documented infection with (-B) or without (-NB) bacteraemia; CDI, clinically documented infection; FUO, fever of unknown origin.

${ }^{a}$ No data available for patients from the study by Robatel et al. ${ }^{14}$

${ }^{b}$ Median $\mathrm{CL}_{C R}$ for each patient not receiving CRRT was retrieved for assigning the patient to the appropriate $\mathrm{CL}_{\mathrm{CR}}$ subgroup.

'Seven patients in the model-building dataset and three in the external validation dataset received CRRT for a limited period of time during their ICU stay. They were assigned to the CRRT group and one of the calculated $\mathrm{CL}_{\mathrm{CR}}$ subgroups.

${ }^{\mathrm{d}}$ CRRT includes haemofiltration and haemodiafiltration.

eEight patients presented multiple infectious episodes.

\section{Base model}

A two-compartment model including $\mathrm{CL}_{\mathrm{CRRT}}$ with interpatient variability assigned to $\mathrm{CL}_{\text {res }}, \mathrm{S}_{\mathrm{c}}$ and central volume of distribution $\left(\mathrm{V}_{\mathrm{c}}\right)$ best described the rich meropenem dataset collected in the
Robatel et al. ${ }^{14}$ study ( $\Delta \mathrm{OFV}=-218, P<0.001$ compared with a one-compartment model). No-fit improvement was observed by assigning an interpatient variability to the intercompartmental clearance $(Q)$ or to the peripheral volume of distribution $\left(V_{p}\right)$ or by using three compartments ( $\triangle \mathrm{OFV}>-2.5, P=0.11$ ). Residual variability for plasma and filtrate-dialysate concentrations was described by a mixed error model. The PK model applied to the entire model-building dataset with the additional estimation of $\mathrm{CL}_{n-}$ CRRT provided an adequate characterization of the data. Equal interpatient variability was associated with both clearances. The final population base parameters with interpatient variability (CV\%) were: $\mathrm{CL}_{\text {no-CRRT }} 8.0 \mathrm{~L} / \mathrm{h}$ (57\%), $\mathrm{CL}_{\text {res }} 3.5 \mathrm{~L} / \mathrm{h}$ (57\%), $\mathrm{S}_{\mathrm{c}} 0.75$ (27\%), $V_{c} 17 \mathrm{~L}(60 \%), Q 13 \mathrm{~L} / \mathrm{h}$ and $V_{p} 16 \mathrm{~L}$. The calculated mean total clearance was $4.8 \mathrm{~L} / \mathrm{h}$ (IQR $3.5-6.3 \mathrm{~L} / \mathrm{h}$ ) in patients undergoing CRRT.

\section{Covariate analysis}

Univariate analyses showed a significant 62\% lower meropenem $\mathrm{CL}_{\text {no-CRRT }}$ in patients with impaired $\left(\mathrm{CL}_{\mathrm{CR}} 30 \mathrm{~mL} / \mathrm{min}\right)$ versus normal $\left(\mathrm{CL}_{\mathrm{CR}} 100 \mathrm{~mL} / \mathrm{min}\right)$ renal function $(\Delta \mathrm{OFV}=-66, \quad P<0.001)$. Furthermore, a $100 \%$ decrease in $\mathrm{CL}_{\text {no-CRRT }}$ was observed by doubling the age compared with the median population value $(\Delta \mathrm{OFV}=-15, P=0.0001)$. No associations were identified between age and $\mathrm{CL}_{\mathrm{CRRT}}(\triangle \mathrm{OFV}=-2.9, P=0.09)$ or between gender or body weight and $\mathrm{CL}_{\text {CRRT }} / \mathrm{CL}_{\text {no-CRRT }}(\Delta \mathrm{OFV}>-1.2, P=0.27)$. Body weight on $V_{c}$ using an allometric function resulted in a marked improvement of fit ( $\triangle \mathrm{OFV}=-20, P<0.001)$, but without further improvement by introducing a gender effect $(\triangle \mathrm{OFV}=0, P=1)$. Multivariate analyses and backward deletion allowed discarding the effect of age on $\mathrm{CL}_{\text {no-CRRT }}$ while maintaining the effect of $\mathrm{CL}_{\mathrm{CR}}$ in addition to body weight on $V_{c}$. The final model parameter values with bootstrap estimations are presented in Table 4.

\section{Model validation}

The model was reliable: the obtained parameter estimates lied within the bootstrap $95 \% \mathrm{CI}$, differing by $<6 \%$ from the bootstrap median values. The predictive model performance was corroborated by the pcVPC shown in Figure 1. Insignificant biases of 10\% (95\% CI - 5\% to $28 \%$ ) and $20 \%$ ( $95 \%$ CI $-7 \%$ to $55 \%$ ) at individual and population prediction levels were calculated applying the final model with covariates to the external validation dataset.

\section{Dosing simulations}

PTA values for $100 \% \mathrm{fT}_{>\text {MIC }}$ obtained by Monte Carlo simulations of different recommended dosing regimens for patients with CRRT or $\mathrm{CL}_{\mathrm{CR}}$ from 15 to $>130 \mathrm{~mL} / \mathrm{min}$ are shown in Tables 5 and 6 , respectively, for intermittent administrations, and in Tables 7 and 8, respectively, for continuous infusions.

Using intermittent administration, recommended regimens of $1 / 1.5 \mathrm{~g}$ q12h over $30 \mathrm{~min}$ achieved $90 \%$ PTA for pathogens with MIC $\leq 2 \mathrm{mg} / \mathrm{L}$ in patients undergoing CRRT with a filtration rate of 1000 to $<2000 \mathrm{~mL} / \mathrm{h} ; 1.5 \mathrm{~g}$ q12h or $1 \mathrm{~g}$ q8h schedules achieved adequate PTA in CRRT with a filtration rate of 2000 to $<3000 \mathrm{~mL} / \mathrm{h}$.

Schedules of $0.5 \mathrm{~g}$ q8h and $1.5 \mathrm{~g}$ q12h over 30 min resulted in adequate PTA in subjects with $\mathrm{CL}_{\mathrm{CR}}$ of 15 to $<30 \mathrm{~mL} / \mathrm{min}$. For $\mathrm{CL}_{\mathrm{CR}}$ of 30 to $<60 \mathrm{~mL} / \mathrm{min}, 1$ and $2 \mathrm{~g}$ q12h regimens produced an 
Table 3. $\mathrm{MIC}_{50}$ and $\mathrm{MIC}_{90}$ of documented meropenem-susceptible pathogens

\begin{tabular}{lcll}
\hline Organisms & $N(\%)$ & MIC $_{50}(\mathrm{mg} / \mathrm{L})$ & $\mathrm{MIC}_{90}(\mathrm{mg} / \mathrm{L})$ \\
\hline Gram-negative & & & \\
$\quad$ P. aeruginosa & $20(15.7)$ & 2 & 2 \\
$\quad$ Enterobacter spp. & $20(15.7)$ & 0.125 & 0.125 \\
Escherichia coli & $19(15)$ & 0.125 & 0.125 \\
Klebsiella spp. & $15(11.8)$ & 0.125 & 0.125 \\
$\quad$ Klebsiella pneumoniae & $7(5.5)$ & 0.125 & 0.125 \\
$\quad$ Serratia marcescens & $4(3.1)$ & 0.25 & 0.25 \\
Others & $18(14.2)$ & 0.25 & 2 \\
Subtotal & $96(75.6)$ & 0.125 & 2 \\
Gram-positive & & & \\
$\quad$ Staphylococcus spp. & $18(14.2)$ & 0.5 & 0.5 \\
$\quad$ Staphylococcus aureus & $4(3.1)$ & 0.5 & 0.5 \\
$\quad$ Streptococcus spp. & $10(7.9)$ & 0.125 & 2 \\
$\quad$ Streptococcus pneumoniae & $6(4.7)$ & 0.016 & 0.25 \\
Others & $3(2.4)$ & 2 & 2 \\
Subtotal & $31(24.4)$ & 0.5 & 2 \\
Total & $127(100)$ & 0.125 & 2 \\
& & & \\
\hline
\end{tabular}

ECOFFs, EUCAST epidemiological cut-off values.

MIC $_{50}, 50 \%$ of pathogens have an equal or lower MIC; MIC $_{90}, 90 \%$ of pathogens have an equal or lower MIC. ECOFFs were used when measured MICs of the causative pathogens were not available.

expected PTA for MIC $\leq 1 \mathrm{mg} / \mathrm{L}$, whereas only the second achieved $90 \%$ PTA for MIC $\leq 2 \mathrm{mg} / \mathrm{L}$.

The recommended dosing $1 \mathrm{~g}$ q8h achieves an appropriate PTA for $\mathrm{MIC} \leq 1 \mathrm{mg} / \mathrm{L}$ in patients with $\mathrm{CL}_{\mathrm{CR}}<90 \mathrm{~mL} / \mathrm{min}$. A dose of $2 \mathrm{~g}$ q8h achieves $90 \%$ PTA for MIC $\leq 2 \mathrm{mg} / \mathrm{L}$.

Neither 1 nor $2 \mathrm{~g}$ q8h schedules reached 90\% PTA in subjects with $\mathrm{CL}_{\mathrm{CR}}$ of 90 to $<130 \mathrm{~mL} / \mathrm{min}$ for $\mathrm{MIC}>0.5 \mathrm{mg} / \mathrm{mL}$ : regimens with four or six daily infusions over $120 \mathrm{~min}$ are required. The label doses of 1 and $2 \mathrm{~g}$ q8h barely reach 90\% PTA for MIC $\leq 0.5 \mathrm{mg} / \mathrm{L}$ in patients with ARC, i.e. $\mathrm{CL}_{\mathrm{CR}}$ of $130-160 \mathrm{~mL} / \mathrm{min}$. Only $1 \mathrm{~g}$ q4h infusions over $120 \mathrm{~min}$ reached $90 \%$ PTA for an MIC $\leq 2 \mathrm{mg} / \mathrm{L}$ in these patients.

When using the corresponding total daily dose administered in continuous infusion, $100 \%$ PTA for MIC of $2 \mathrm{mg} / \mathrm{L}$ was reached in all categories of renal function, including ARC.

\section{Discussion}

Meropenem blood concentration data in critically ill patients with susceptible life-threatening infections, including a subgroup undergoing CRRT, were analysed by a population PK approach aimed at evaluating the adequacy of recommended dosing regimens. Visual, internal and external model validations support the accuracy and stability of a two-compartment model with linear elimination. ${ }^{44,45}$ Our estimates of PK parameters are consistent with previous reports. The high distribution volume in our dataset lies within the range of previously reported values. ${ }^{13,14,44-60}$ Among tested covariates, body weight influenced the volume of distribution and $\mathrm{CL}_{\mathrm{CR}}$ determined meropenem clearance in patients not undergoing CRRT. ${ }^{45-47}$ In individuals undergoing
Table 4. Meropenem population PK parameter estimates with bootstrap evaluations

\begin{tabular}{|c|c|c|c|c|}
\hline \multirow[b]{2}{*}{ Parameter } & \multicolumn{2}{|c|}{ Population model } & \multicolumn{2}{|c|}{ Bootstrap evaluation } \\
\hline & estimate & $\operatorname{RSE}^{\mathrm{a}}(\%)$ & estimate & $95 \% \mathrm{CI}^{\mathrm{b}}$ \\
\hline $\mathrm{CL}_{\text {res }}(\mathrm{L} / \mathrm{h})$ & 3.2 & 12 & 3.2 & $(2.5-4.0)$ \\
\hline$S_{c}$ & 0.75 & 8 & 0.76 & $(0.65-0.88)$ \\
\hline $\mathrm{TVCL}_{\text {no-CRRT }}(\mathrm{L} / \mathrm{h})$ & 5.9 & 7 & 5.9 & $(5.2-6.8)$ \\
\hline$\theta_{\mathrm{CLCR}}(\%)$ & 0.71 & 21 & 0.69 & $(0.40-0.94)$ \\
\hline $\operatorname{TVV}_{c}(\mathrm{~L})$ & 16 & 15 & 16 & $(11-21)$ \\
\hline$\theta_{\mathrm{BW}}$ & 1.7 & 19 & 1.7 & $(1.0-2.4)$ \\
\hline$Q(\mathrm{~L} / \mathrm{h})$ & 14 & 9 & 14 & $(12-18)$ \\
\hline$V_{P}(L)$ & 15 & 4 & 15 & $(14-17)$ \\
\hline $\mathrm{BSV}_{\mathrm{CL}}(\mathrm{CV} \%)$ & 40 & 12 & 40 & $(31-49)$ \\
\hline $\mathrm{BSV}_{\mathrm{SC}}(\mathrm{CV} \%)$ & 26 & 23 & 26 & $(14-37)$ \\
\hline $\mathrm{BSV}_{\mathrm{Vc}}(\mathrm{CV} \%)$ & 51 & 15 & 48 & $(17-65)$ \\
\hline$\sigma_{\text {prop rich plasma }}^{\mathrm{C}}(\mathrm{CV} \%)$ & 4.1 & 43 & 4.0 & $(1.0-7.9)$ \\
\hline$\sigma_{\text {add rich plasma }}^{\mathrm{d}}(\mathrm{mg} / \mathrm{L})$ & 2.7 & 16 & 2.6 & $(1.7-3.6)$ \\
\hline$\sigma_{\text {prop rich FD }}^{\mathrm{C}}(\mathrm{CV} \%)$ & 11 & 28 & 11 & $(6-17)$ \\
\hline$\sigma_{\text {add rich FD }}^{\mathrm{d}}(\mathrm{mg} / \mathrm{L})$ & 2.5 & 13 & 2.5 & $(1.7-3.1)$ \\
\hline$\sigma_{\text {prop TDM routine }}^{c}(\mathrm{CV} \%)$ & 52 & 15 & 52 & $(36-67)$ \\
\hline$\sigma_{\text {prop ongoing trial }}^{c}(\mathrm{CV} \%)$ & 38 & 7 & 37 & $(31-43)$ \\
\hline
\end{tabular}

$\mathrm{CL}_{\mathrm{CRRT}}=\mathrm{CL}_{\text {res }}+\mathrm{S}_{\mathrm{C}} * \mathrm{Q}_{\mathrm{FD}}$.

$\mathrm{CL}_{\text {no-CRRT }}=\operatorname{TVCL} L_{\text {no-CRRT }} *\left(1+\theta_{\mathrm{CLCR}} \frac{\text { CLCR-median } \mathrm{CLCR}}{\text { medion CLCR }}\right)$.

$V_{c}=\operatorname{TVV}_{c} *\left(\frac{B W}{\text { medBW }}\right) \theta_{B W}$.

$\mathrm{CL}_{\mathrm{CRRT}}$, total meropenem clearance in patients undergoing $C R R T ; \mathrm{CL}_{\text {res }}$, meropenem residual clearance in CRRT patients; $S_{c}$, sieving coefficient; $Q_{\mathrm{FD}}$, FD flow; FD, filtrate-dialysate; $\mathrm{TVCL}_{\mathrm{no}-\mathrm{CRRT}}$, typical value of clearance for patients not receiving CRRT; $\theta_{C L C R}$, increase in $\mathrm{CL}_{\text {no-CRRT }}$ due to $\mathrm{CL}_{C R}$ variation with respect to its median value (median $\mathrm{CL}_{\mathrm{CR}}=44 \mathrm{~mL} / \mathrm{min}$ ); $\mathrm{TVV}_{c}$, typical value of the $V_{c} ; \theta_{\mathrm{BW}}$, allometric power describing the effect of BW normalized by its median value (median BW $=72 \mathrm{~kg}$ ); BW, body weight; $V_{c}$, central volume of distribution; RSE, relative standard errors; BSV, between-subject variability.

${ }^{a}$ RSE are defined as the ratio between the standard error and the parameter estimate retrieved directly from NONMEM ${ }^{\circledR}$ output files.

b95\% bootstrap CI.

'Proportional component of the residual variability.

${ }^{\mathrm{d}}$ Additive component of the residual variability.

CRRT, residual clearance accounted for a large part of total renal clearance, with a $\mathrm{CL}_{\text {res }} / \mathrm{CL}_{\text {tot }}$ ratio of 0.63 . This finding, comparable with those in previous reports, ${ }^{13,14,42,44,48-51,53,55,57,59,61}$ may be explained by a higher non-renal clearance, which was shown to increase from $20 \%$ in healthy patients to $50 \%$ in patients with severe renal impairment, particularly in those undergoing CRRT. An increased hepatic or spontaneous degradation of meropenem into inactivated metabolites is presumed in these patients. ${ }^{62,63}$

The large intra- and inter-individual variability characterizing meropenem PK confirms that individualized dosing is a key point in optimizing drug exposure and antimicrobial efficacy. ${ }^{6,8}$ TDM is useful for identifying patients in whom meropenem blood concentrations lay outside the targeted therapeutic interval and who may benefit from individual dosing adjustment. ${ }^{64-66}$ As TDM is not routinely available for real-time guidance for dose adjustments, optimizing dosing regimens according to $\mathrm{CL}_{C R}$ is an alternative 


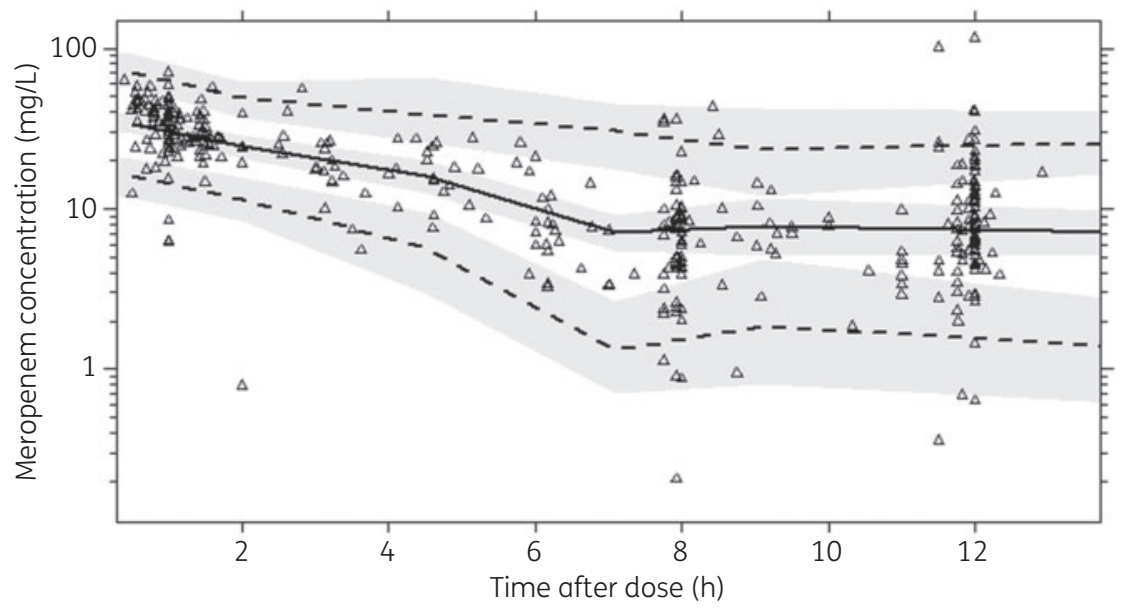

Figure 1. Prediction-corrected visual predictive check of the final PK model with observed meropenem concentrations (triangles), median simulated population prediction (solid line) with 90\% prediction intervals (90\% PI, dashed lines). Shaded areas represent the 95\% CI of model-predicted percentiles.

Table 5. PTA for achieving $100 \% \mathrm{fT}_{>\mathrm{MIC}}$ for different simulated meropenem dosing regimens in $70 \mathrm{~kg}$ patients undergoing CRRT as a function of CVVHDF filtration rate

\begin{tabular}{|c|c|c|c|c|c|c|c|c|c|c|}
\hline \multirow[b]{2}{*}{ Filtration rate/dosing regimen } & \multicolumn{10}{|c|}{ PTA (\%) of $100 \% \mathrm{fT}_{>\mathrm{MIC}}$ at the indicated MIC (mg/L) } \\
\hline & 0.125 & 0.25 & 0.5 & 1 & 2 & 4 & 8 & 16 & 32 & 64 \\
\hline \multicolumn{11}{|l|}{1000 to $<2000 \mathrm{~mL} / \mathrm{min}$} \\
\hline $1 \mathrm{gq} 12 \mathrm{~h}$ & 100 & 100 & 99.4 & 96.9 & 90.4 & 75.6 & 47 & 14.8 & 1.6 & 0.1 \\
\hline $1.5 \mathrm{~g} \mathrm{q12h}$ & 100 & 99.9 & 99.8 & 98.8 & 95.7 & 88.2 & 69.2 & 35.3 & 5.5 & 0.2 \\
\hline \multicolumn{11}{|l|}{2000 to $<3000 \mathrm{~mL} / \mathrm{min}$} \\
\hline $1 \mathrm{gq} 12 \mathrm{~h}$ & 99.5 & 98.8 & 97.7 & 94 & 84.8 & 64.7 & 32.7 & 7.1 & 0.3 & 0 \\
\hline $1.5 \mathrm{~g} \mathrm{q} 12 \mathrm{~h}$ & 99.9 & 99.8 & 99.2 & 97.2 & 90.8 & 79.8 & 52.8 & 21.7 & 2.6 & 0 \\
\hline $1 \mathrm{gq} 8 \mathrm{~h}$ & 100 & 99.9 & 99.7 & 99.1 & 97.7 & 90.4 & 68.9 & 33.3 & 5.3 & 0.1 \\
\hline
\end{tabular}

Perfusion time was 30 min.

Results are shown in bold for an MIC of $2 \mathrm{mg} / \mathrm{L}$, corresponding to the $\mathrm{MIC}_{90}$ of the isolated pathogens in the present study and to the clinical MIC breakpoint for meropenem susceptibility of the majority of bacteria according to EUCAST.

Alternative regimen showing a better PTA according to the renal function is shown in italics.

approach, particularly in critically ill populations with severe infections and altered renal elimination that may result in treatment failure. ${ }^{7,19,21-23}$

Considering a PK/PD target of $100 \% f T_{>M I C}$, we observed that the risk of suboptimal drug exposure is low with recommended dosing regimens for an $\mathrm{MIC}_{50}$ of $0.125 \mathrm{mg} / \mathrm{L}$. However, as species identification and antibacterial susceptibility of the causative pathogen are unknown when empirical meropenem is started, prompt coverage for the worst-case scenario needs to be achieved. In our study, the $\mathrm{MIC}_{90}$ was $2 \mathrm{mg} / \mathrm{L}$, which corresponds to the clinical breakpoint for meropenem susceptibility of the majority of bacteria according to EUCAST. ${ }^{30} \mathrm{~A}$ meropenem concentration of $2 \mathrm{mg} / \mathrm{L}$ is thus an appropriate MIC target for empirical antibacterial coverage in critically ill patients with severe infections. Our simulations emphasize the need for adjustment of recommended dosing regimens. While these schedules result in appropriate PTA in patients with impaired renal function, higher doses are needed when $\mathrm{CL}_{C R}$ is $>60 \mathrm{~mL} / \mathrm{min}$. A combination of higher doses, shorter dosing intervals or longer infusion times represents an efficient strategy for optimizing PTA in intermittent administration, e.g. with $1.5 \mathrm{~g}$ q6h or $0.5 \mathrm{~g}$ q4h infused over $120 \mathrm{~min}$. Identification of patients with ARC ( $\mathrm{CL}_{\mathrm{CR}}$ of $\left.130-160 \mathrm{~mL} / \mathrm{min}\right)$ is crucial, as standard meropenem regimens are insufficient in intermittent administration. Only a regimen of $1 \mathrm{~g} q 4 \mathrm{~h}$ infused over 120 min reaches an appropriate PTA for an MIC of $2 \mathrm{mg} / \mathrm{L}$. Continuous infusion is also an option for optimally ensuring MIC coverage over the whole dosing interval in patients with ARC. These observations corroborate recent reports and highlight the importance for clinical ICU practice of meropenem regimen adjustment in patients with ARC. ${ }^{7,19,21-23}$

According to our data, the PK/PD target 100\% fT $>_{4 \times \text { MIC }}$ (i.e. $8 \mathrm{mg} / \mathrm{L}$ in the empirical setting) would not be achievable with intermittent meropenem infusions, at least not without a significant increase in the daily dosage. Whereas our simulations show that the recommended regimens fail to achieve this target at any level of renal function, a systematic use of continuous infusion would 
Table 6. PTA for achieving $100 \% \mathrm{fT}_{>\mathrm{MIC}}$ for different simulated meropenem dosing regimens in $70 \mathrm{~kg}$ patients as a function of renal creatinine clearance

PTA (\%) of $100 \% \mathrm{fT}_{>\text {MIC }}$ at the indicated MIC $(\mathrm{mg} / \mathrm{L})$

\begin{tabular}{|c|c|c|c|c|c|c|c|c|c|c|}
\hline $\begin{array}{l}\mathrm{CL}_{\mathrm{CR}}(\mathrm{mL} / \mathrm{min}) / \text { dosing } \\
\text { regimen }\end{array}$ & 0.125 & 0.25 & 0.5 & 1 & 2 & 4 & 8 & 16 & 32 & 64 \\
\hline \multicolumn{11}{|l|}{15 to $<30 \mathrm{~mL} / \mathrm{min}$} \\
\hline $0.5 \mathrm{~g} \mathrm{q} 8 \mathrm{~h}$ & 100 & 99.9 & 99.6 & 99.4 & 98 & 90.7 & 63.5 & 22.2 & 2.2 & 0 \\
\hline $1.5 \mathrm{~g} \mathrm{q} 12 \mathrm{~h}$ & 100 & 100 & 100 & 99.6 & 97.5 & 92.5 & 79.4 & 48.3 & 14.7 & 1.1 \\
\hline \multicolumn{11}{|l|}{30 to $<60 \mathrm{~mL} / \mathrm{min}$} \\
\hline $1 \mathrm{gq} 12 \mathrm{~h}$ & 99.7 & 98.8 & 95.7 & 89.4 & 76.3 & 51.4 & 24.9 & 6.1 & 0.7 & 0 \\
\hline $2 \mathrm{gq} 12 \mathrm{~h}$ & 99.9 & 99.4 & 98.7 & 96.6 & 89.5 & 75.4 & 49.8 & 24.1 & 6.1 & 0.7 \\
\hline \multicolumn{11}{|l|}{60 to $<90 \mathrm{~mL} / \mathrm{min}$} \\
\hline $1 \mathrm{~g} \mathrm{q} 8 \mathrm{~h}$ & 99.9 & 99.4 & 96.9 & 91.3 & 79.4 & 53.8 & 22.5 & 4.1 & 0.2 & 0 \\
\hline $2 \mathrm{gq} 8 \mathrm{~h}$ & 100 & 100 & 99.8 & 97.8 & 92.5 & 79.4 & 52.8 & 20.6 & 4 & 0.1 \\
\hline \multicolumn{11}{|l|}{90 to $<130 \mathrm{~mL} / \mathrm{min}$} \\
\hline $1 \mathrm{~g} \mathrm{q} 8 \mathrm{~h}$ & $99.2 / 99.81^{a}$ & $96.2 / 98.1^{a}$ & $89.5 / 94.4^{a}$ & $75.5 / 83.1^{a}$ & $53.1 / 60.8^{a}$ & $27.3 / 34.1^{a}$ & $6.4 / 9^{a}$ & $0.8 / 1.2^{a}$ & $0 / 0^{a}$ & $0 / 0^{a}$ \\
\hline $2 \mathrm{gq} 8 \mathrm{~h}$ & $99.4 / 100^{a}$ & $98.3 / 99.4^{a}$ & $95.8 / 97.7^{a}$ & $89.3 / 93.4^{a}$ & $73.3 / 80.9^{a}$ & $49 / 58.5^{a}$ & $26.7 / 34.4^{a}$ & $6.4 / 9.4^{a}$ & $0.8 / 1.1^{a}$ & $0 / 0^{a}$ \\
\hline $1.5 \mathrm{gq} 6 \mathrm{~h}$ & $100 / 100^{a}$ & $99.9 / 100^{a}$ & $99.5 / 99.9^{a}$ & $95.6 / 98.6^{a}$ & $85.3 / 92.3^{a}$ & $67.1 / 76.9^{a}$ & $37.5 / 48^{a}$ & $12.7 / 17^{a}$ & $1.8 / 2.9^{\mathrm{a}}$ & $0 / 0^{a}$ \\
\hline $1 \mathrm{~g} q 4 \mathrm{~h}$ & $100 / 100^{a}$ & $100 / 100^{a}$ & $100 / 100^{a}$ & $99.5 / 100^{a}$ & $96 / 99.1^{a}$ & $83 / 91.6^{a}$ & $54.9 / 69.6^{a}$ & $22.2 / 31.5^{a}$ & $2.7 / 4.1^{a}$ & $0.1 / 0.1^{a}$ \\
\hline \multicolumn{11}{|l|}{$>130 \mathrm{~mL} / \mathrm{min}$} \\
\hline $1 \mathrm{~g} \mathrm{q} 8 \mathrm{~h}$ & $94.2 / 97^{a}$ & $86.5 / 92.2^{a}$ & $67.6 / 77.6^{a}$ & $47.5 / 57.4^{a}$ & $26.7 / 32.9^{a}$ & $10.5 / 14.5^{a}$ & $1.6 / 2.6^{a}$ & $0.1 / 0.1^{a}$ & $0 / 0^{a}$ & $0 / 0^{a}$ \\
\hline $2 \mathrm{~g} \mathrm{q} 8 \mathrm{~h}$ & $98.2 / 99.1^{a}$ & $94.9 / 97.5^{a}$ & $85.5 / 92.1^{a}$ & $71.2 / 78.9^{a}$ & $50.1 / 60.9^{a}$ & $27.1 / 36^{a}$ & $8.1 / 12.3^{a}$ & $1.1 / 2.4^{a}$ & $0 / 0^{a}$ & $0 / 0^{a}$ \\
\hline $1.5 \mathrm{gq} 6 \mathrm{~h}$ & $99.5 / 100^{a}$ & $98.8 / 99.3^{a}$ & $96.2 / 98.1^{a}$ & $88 / 93.3^{a}$ & $67.5 / 80.7^{a}$ & $40.6 / 53.2^{a}$ & $14.6 / 24.2^{a}$ & $2.1 / 4.1^{a}$ & $0 / 0.5^{a}$ & $0 / 0^{a}$ \\
\hline $1 \mathrm{gq} 4 \mathrm{~h}$ & $100 / 100^{a}$ & $100 / 100^{a}$ & $99.4 / 100^{a}$ & $97.1 / 99.1^{a}$ & $87.3 / 95^{a}$ & $65 / 79.7^{a}$ & $33.2 / 47.7^{a}$ & $8.4 / 13.7^{a}$ & $0.4 / 0.7^{a}$ & $0 / 0^{a}$ \\
\hline
\end{tabular}

Perfusion time was 30 min unless indicated.

Results shown in bold are for an MIC of $2 \mathrm{mg} / \mathrm{L}$, corresponding to the $\mathrm{MIC}_{90}$ of the isolated pathogens in the present study and to the clinical MIC breakpoint for meropenem susceptibility of the majority of bacteria according to EUCAST.

Alternative regimens showing a better PTA according to the renal function are shown in italics.

aPerfusion time was $120 \mathrm{~min}$.

Table 7. PTA for achieving $100 \% \mathrm{fT}_{>\mathrm{MIC}}$ using different simulated meropenem dosing regimens of continuous infusion in $70 \mathrm{~kg}$ patients undergoing CRRT as a function of CVVHDF filter rate

\begin{tabular}{|c|c|c|c|c|c|c|c|c|c|c|}
\hline \multirow[b]{2}{*}{ Filtration rate/dosing regimen } & \multicolumn{10}{|c|}{ PTA $(\%)$ of $100 \% f T_{>\text {MIC }}$ at the indicated MIC } \\
\hline & 0.125 & 0.25 & 0.5 & 1 & 2 & 4 & 8 & 16 & 32 & 64 \\
\hline \multicolumn{11}{|l|}{1000 to $<2000 \mathrm{~mL} / \mathrm{min}$} \\
\hline $2 \mathrm{~g} \mathrm{q} 24 \mathrm{~h}$ & 100 & 100 & 100 & 100 & 100 & 100 & 98.7 & 68.3 & 10.8 & 0.2 \\
\hline $3 \mathrm{~g} \mathrm{q} 24 \mathrm{~h}$ & 100 & 100 & 100 & 100 & 100 & 100 & 99.9 & 92.3 & 39.5 & 2.9 \\
\hline \multicolumn{11}{|l|}{2000 to $<3000 \mathrm{~mL} / \mathrm{min}$} \\
\hline $1.5 \mathrm{~g} \mathrm{q} 24 \mathrm{~h}$ & 100 & 100 & 100 & 100 & 100 & 99.6 & 83.3 & 22.7 & .8 & 0 \\
\hline $2 \mathrm{~g} \mathrm{q} 24 \mathrm{~h}$ & 100 & 100 & 100 & 100 & 100 & 100 & 95.3 & 51.7 & 4.4 & 0.1 \\
\hline
\end{tabular}

Results for an MIC of $2 \mathrm{mg} / \mathrm{L}$ are shown in bold, corresponding to the MIC $_{90}$ of the isolated pathogens in the present study and to the clinical MIC breakpoint for meropenem susceptibility of the majority of bacteria according to EUCAST.

achieve target attainment. Indeed, continuous infusion shows adequate PTA for both targets (i.e. $100 \% f T_{>M I C}$ and $100 \%$ $\left.f T>_{4 \times M I C}\right)$, even with a standard dose of $3 \mathrm{~g} /$ day in patients with ARC. Waiting for clinical evidence on the benefit of this higher PK/ PD target for patient outcomes, intermittent meropenem therapy is a suitable option for optimizing microbiological efficacy with a meropenem trough concentration $>2 \mathrm{mg} / \mathrm{L}$ ( $\mathrm{MIC}_{90}$ in our population and EUCAST susceptibility MIC breakpoint) as a conservative and recognized standard for PK/PD target.
The estimation of renal function based on $\mathrm{CL}_{\mathrm{CR}}$ correlates poorly with the measured renal function in ICU patients, which represents a limitation in our study. ${ }^{67,68}$ Although the adequacy of pooling patients investigated in different settings may be challenged, this heterogeneity has been accounted for by using distinct residual error models, which best preserved model robustness. EUCAST cut-off MICs were used when MICs of the causative pathogens were not available. Although this approach possibly overestimated the $\mathrm{MIC}_{90}$ in our ICU setting, a strategy for empirical meropenem 
Table 8. PTA for achieving $100 \% \mathrm{fT}_{>\mathrm{MIC}}$ using different simulated meropenem dosing regimens of continuous infusion in $70 \mathrm{~kg}$ patients as a function of renal creatinine clearance

\begin{tabular}{|c|c|c|c|c|c|c|c|c|c|c|}
\hline \multirow[b]{2}{*}{$\mathrm{CL}_{\mathrm{CR}} /$ dosing regimen } & \multicolumn{10}{|c|}{ PTA (\%) of $100 \% f T_{>\text {MIC }}$ at the indicated MIC (mg/L) } \\
\hline & 0.125 & 0.25 & 0.5 & 1 & 2 & 4 & 8 & 16 & 32 & 64 \\
\hline \multicolumn{11}{|l|}{15 to $<30 \mathrm{~mL} / \mathrm{min}$} \\
\hline $1.5 \mathrm{~g} \mathrm{q} 24 \mathrm{~h}$ & 100 & 100 & 100 & 100 & 100 & 100 & 97.3 & 59.2 & 6.5 & 0.1 \\
\hline $3 \mathrm{~g} \mathrm{q} 24 \mathrm{~h}$ & 100 & 100 & 100 & 100 & 100 & 100 & 100 & 96 & 57.1 & 6 \\
\hline \multicolumn{11}{|l|}{30 to $<60 \mathrm{~mL} / \mathrm{min}$} \\
\hline $2 \mathrm{~g} \mathrm{q} 24 \mathrm{~h}$ & 100 & 100 & 100 & 100 & 100 & 99.9 & 93 & 41.1 & 2.5 & 0 \\
\hline $4 \mathrm{~g} \mathrm{q} 24 \mathrm{~h}$ & 100 & 100 & 100 & 100 & 100 & 100 & 100 & 92.7 & 40.8 & 1.6 \\
\hline \multicolumn{11}{|l|}{60 to $<90 \mathrm{~mL} / \mathrm{min}$} \\
\hline $3 \mathrm{~g} \mathrm{q} 24 \mathrm{~h}$ & 100 & 100 & 100 & 100 & 100 & 99.9 & 91.6 & 38.4 & 1.9 & 0 \\
\hline $6 \mathrm{~g} \mathrm{q} 24 \mathrm{~h}$ & 100 & 100 & 100 & 100 & 100 & 100 & 99.9 & 92.8 & 40.2 & 2.2 \\
\hline \multicolumn{11}{|l|}{90 to $<130 \mathrm{~mL} / \mathrm{min}$} \\
\hline $3 \mathrm{~g} \mathrm{q} 24 \mathrm{~h}$ & 100 & 100 & 100 & 100 & 100 & 98.9 & 70.4 & 12.1 & 0.3 & 0 \\
\hline $6 \mathrm{~g} \mathrm{q} 24 \mathrm{~h}$ & 100 & 100 & 100 & 100 & 100 & 100 & 99.6 & 73.6 & 12.8 & 0.6 \\
\hline \multicolumn{11}{|l|}{$>130 \mathrm{~mL} / \mathrm{min}$} \\
\hline $3 \mathrm{~g} \mathrm{q} 24 \mathrm{~h}$ & 100 & 100 & 100 & 100 & 100 & 96.8 & 50.7 & 5.2 & 0 & 0 \\
\hline $6 \mathrm{~g} \mathrm{q} 24 \mathrm{~h}$ & 100 & 100 & 100 & 100 & 100 & 100 & 96.5 & 49.3 & 3.9 & 0.1 \\
\hline
\end{tabular}

Results for an MIC of $2 \mathrm{mg} / \mathrm{L}$ are shown in bold, corresponding to the $\mathrm{MIC}_{90}$ of the isolated pathogens in the present study and to the clinical MIC breakpoint for meropenem susceptibility of the majority of bacteria according to EUCAST.

therapy in critically ill patients with severe infections that targets the coverage of an MIC of $2 \mathrm{mg} / \mathrm{L}$, the clinical breakpoint for susceptibility in the majority of microorganisms, is suitable for optimizing clinical outcome. Finally, data regarding CRRT may vary according to haemofilter type and age, which might limit the application of our simulation in different CRRT settings.

In comparison with other studies, we present here a model based on a large sample size, which was externally validated with an independent dataset of critically ill patients with similar clinical characteristics. This methodological approach is often lacking in PK/ PD studies and represents an advantage of the present study conferring robustness to our observations. ${ }^{69}$ The adequacy of multiple meropenem dosing regimens over the whole range of renal function, from CRRT to ARC, was assessed with both short and prolonged intermittent infusions as well as with continuous infusions. PTA simulations over a large range of MIC values enable ICU physicians to optimize dosing strategies according to the PK/PD target (i.e. 100\% $f T_{>\mathrm{MIC}}$ or $100 \% \mathrm{fT}_{>4 \times \mathrm{MIC}}$ ) in the empirical setting (coverage of $\mathrm{MIC}_{90}$ or of the susceptibility MIC breakpoint) or according to the actually documented MIC in a given patient. Finally, insufficient antimicrobial coverage markedly characterizes patients with normal or augmented renal function. Efforts to optimize the use of meropenem should focus on this particular population. This is in agreement with recent reports highlighting the urgent need for sensitizing ICU physicians to the clinical efficiency of individualized meropenem dosing regimens in critically ill patients with $A R C .^{7,19,21-23}$

\section{Conclusions}

The recommended meropenem dosing regimens in ICU patients with normal or augmented renal clearance do not ensure coverage of pathogens with MICs within the susceptible range.
Strategies combining a higher dose, an increased number of daily administrations and prolonged infusion time, or continuous infusion, are required to optimize meropenem exposure and antimicrobial efficacy in susceptible life-threatening infections.

\section{Acknowledgements}

We warmly thank Brigitte Therriault and David Jenny for outstanding assistance in data extraction from the ICU database as well as Aurélie Guillet and Corine Guyaz for data collection in the TDM study.

\section{Funding}

This project received unrestricted grant support from the Foundation for the Advancement in Medical Microbiology and Infectious Diseases (FAMMID), Lausanne, Switzerland.

\section{Transparency declarations}

None to declare.

\section{References}

1 Angus DC, Linde-Zwirble WT, Lidicker J et al. Epidemiology of severe sepsis in the United States: analysis of incidence, outcome, and associated costs of care. Crit Care Med 2001; 29: 1303-10.

2 Brun-Buisson C, Meshaka P, Pinton P et al. EPISEPSIS: a reappraisal of the epidemiology and outcome of severe sepsis in French intensive care units. Intensive Care Med 2004; 30: 580-8.

3 Stiermaier T, Herkner $\mathrm{H}$, Tobudic S et al. Incidence and long-term outcome of sepsis on general wards and in an ICU at the General Hospital of Vienna: an observational cohort study. Wien Klin Wochenschr 2013; 125: 302-8. 
4 Sakr Y, Elia C, Mascia L et al. Epidemiology and outcome of sepsis syndromes in Italian ICUs: a muticentre, observational cohort study in the region of Piedmont. Minerva Anestesiol 2013; 79: 993-1002.

5 Seyler L, Cotton F, Taccone FS et al. Recommended $\beta$-lactam regimens are inadequate in septic patients treated with continuous renal replacement therapy. Crit Care 2011; 15: R137.

6 Roberts JA, Abdul-Aziz MH, Lipman J et al. Individualised antibiotic dosing for patients who are critically ill: challenges and potential solutions. Lancet Infect Dis 2014; 14: 498-509.

7 Ehmann L, Zoller M, Minichmayr IK et al. Role of renal function in risk assessment of target non-attainment after standard dosing of meropenem in critically ill patients: a prospective observational study. Crit Care 2017; 21: 263.

8 Braune S, König C, Roberts JA et al. Pharmacokinetics of meropenem in septic patients on sustained low-efficiency dialysis: a population pharmacokinetic study. Crit Care 2018; 22: 25.

9 Roberts JA, Paul SK, Akova M et al. DALI: defining antibiotic levels in intensive care unit patients: are current $\beta$-lactam antibiotic doses sufficient for critically ill patients? Clin Infect Dis 2014; 58: 1072-83.

10 Wiseman LR, Wagstaff AJ, Brogden RN et al. Meropenem. A review of its antibacterial activity, pharmacokinetic properties and clinical efficacy. Drugs 1995; 50: 73-101.

11 Craig WA. The pharmacology of meropenem, a new carbapenem antibiotic. Clin Infect Dis 1997; 24 Suppl 2: S266-75.

12 Pfizer. Meronem i.v. http://www.swissmedicinfo.ch/.

13 Krueger WA, Schroeder TH, Hutchison M et al. Pharmacokinetics of meropenem in critically ill patients with acute renal failure treated by continuous hemodiafiltration. Antimicrob Agents Chemother 1998; 42: 2421-4.

14 Robatel C, Decosterd LA, Biollaz J et al. Pharmacokinetics and dosage adaptation of meropenem during continuous venovenous hemodiafiltration in critically ill patients. J Clin Pharmacol 2003; 43: 1329-40.

15 Drusano GL. Antimicrobial pharmacodynamics: critical interactions of 'bug and drug'. Nat Rev Microbiol 2004; 2: 289-300.

16 Craig WA. Pharmacokinetic/pharmacodynamic parameters: rationale for antibacterial dosing of mice and men. Clin Infect Dis 1998; 26: 1-10; quiz 11-2.

17 Li C, Du X, Kuti JL et al. Clinical pharmacodynamics of meropenem in patients with lower respiratory tract infections. Antimicrob Agents Chemother 2007; 51: 1725-30.

18 Ariano RE, Nyhlén A, Donnelly JP et al. Pharmacokinetics and pharmacodynamics of meropenem in febrile neutropenic patients with bacteremia. Ann Pharmacother 2005; 39: 32-8.

19 Abdul-Aziz MH, Lipman J, Roberts JA. Identifying 'at-risk' patients for suboptimal $\beta$-lactam exposure in critically ill patients with severe infections. Crit Care 2017; 21: 283.

20 Udy AA, Roberts JA, Shorr AF et al. Augmented renal clearance in septic and traumatized patients with normal plasma creatinine concentrations: identifying at-risk patients. Crit Care 2013; 17: R35.

21 Sjövall F, Alobaid AS, Wallis SC et al. Maximally effective dosing regimens of meropenem in patients with septic shock. J Antimicrob Chemother 2018; 73: 191-8.

22 Minichmayr IK, Roberts JA, Frey OR et al. Development of a dosing nomogram for continuous-infusion meropenem in critically ill patients based on a validated population pharmacokinetic model. J Antimicrob Chemother 2018; 73: 1330-9.

23 Jacobs A, Taccone FS, Roberts JA et al. $\beta$-lactam dosage regimens in septic patients with augmented renal clearance. Antimicrob Agents Chemother 2018; 62: AAC.02534-17.

24 Udy AA, Varghese JM, Altukroni $M$ et al. Subtherapeutic initial $\beta$ lactam concentrations in select critically ill patients: association between augmented renal clearance and low trough drug concentrations. Chest 2012; 142: 30-9.

25 Le Gall JR, Lemeshow S, Saulnier F. A new Simplified Acute Physiology Score (SAPS II) based on a European/North American multicenter study. JAMA 1993; 270: 2957-63.

26 Knaus WA, Draper EA, Wagner DP et al. APACHE II: a severity of disease classification system. Crit Care Med 1985; 13: 818-29.

27 Cockcroft DW, Gault MH. Prediction of creatinine clearance from serum creatinine. Nephron 1976; 16: 31-41.

28 Immunocompromised Host Society. The design, analysis, and reporting of clinical trials on the empirical antibiotic management of the neutropenic patient. Report of a consensus panel. J Infect Dis 1990; 161: 397-401.

29 Singer M, Deutschman CS, Seymour CW et al. The Third International Consensus Definitions for Sepsis and Septic Shock (Sepsis-3). JAMA 2016; 315: 801-10.

30 European Committee on Antimicrobial Susceptibility Testing. Breakpoint Tables for Interpretation of MICs and Zone Diameters. Version 4.0. http:// www.eucast.org/fileadmin/src/media/PDFs/EUCAST_files/Breakpoint_tables/ Breakpoint_table_v_4.0.pdf.

31 Robatel C, Buclin T, Eckert P et al. Determination of meropenem in plasma and filtrate-dialysate from patients under continuous veno-venous haemodiafiltration by SPE-LC. J Pharm Biomed Anal 2002; 29: 17-33.

32 US Dept of Health and Human Services. Bioanalytical Method Validation: Guidance for Industry. https://www.fda.gov/downloads/Drugs/Guidance/ ucm070107.pdf.

33 Shah VP, Midha KK, Findlay JW et al. Bioanalytical method validation-a revisit with a decade of progress. Pharm Res 2000; 17: 1551-7.

34 Shah VP, Midha KK, Dighe S et al. Analytical methods validation: bioavailability, bioequivalence and pharmacokinetic studies. Conference report. Eur J Drug Metab Pharmacokinet 1991; 16: 249-55.

35 Matuszewski BK. Standard line slopes as a measure of a relative matrix effect in quantitative HPLC-MS bioanalysis. J Chromatogr B Analyt Technol Biomed Life Sci 2006; 830: 293-300.

36 Matuszewski BK, Constanzer ML, Chavez-Eng CM. Strategies for the assessment of matrix effect in quantitative bioanalytical methods based on HPLC-MS/MS. Anal Chem 2003; 75: 3019-30.

37 Beal S, Sheiner LB, Boeckmann A et al. NONMEM User's Guide (19892009). Ellicott City, MD, USA: Icon Development Solutions, 2009.

38 Lindbom L, Pihlgren P, Jonsson EN. PsN-Toolkit-a collection of computer intensive statistical methods for non-linear mixed effect modeling using NONMEM. Comput Methods Programs Biomed 2005; 79: 241-57.

39 Lindbom L, Ribbing J, Jonsson EN. Perl-speaks-NONMEM (PsN)—a Perl module for NONMEM related programming. Comput Methods Programs Biomed 2004; 75: 85-94.

40 Bergstrand M, Hooker AC, Wallin JE et al. Prediction-corrected visual predictive checks for diagnosing nonlinear mixed-effects models. AAPS J 2011; 13: 143-51.

41 Jonsson EN, Karlsson MO. Xpose-an S-PLUS based population pharmacokinetic/pharmacodynamic model building aid for NONMEM. Comput Methods Programs Biomed 1999; 58: 51-64.

42 Isla A, Maynar J, Sánchez-Izquierdo JA et al. Meropenem and continuous renal replacement therapy: in vitro permeability of 2 continuous renal replacement therapy membranes and influence of patient renal function on the pharmacokinetics in critically ill patients. J Clin Pharmacol 2005; 45: 1294-304.

43 Sheiner LB, Beal SL. Some suggestions for measuring predictive performance. J Pharmacokinet Biopharm 1981; 9: 503-12.

44 Isla A, Rodríguez-Gascón A, Trocóniz IF et al. Population pharmacokinetics of meropenem in critically ill patients undergoing continuous renal replacement therapy. Clin Pharmacokinet 2008; 47: 173-80. 
45 Crandon JL, Ariano RE, Zelenitsky SA et al. Optimization of meropenem dosage in the critically ill population based on renal function. Intensive Care Med 2011; 37: 632-8.

46 Varghese JM, Jarrett P, Wallis SC et al. Are interstitial fluid concentrations of meropenem equivalent to plasma concentrations in critically ill patients receiving continuous renal replacement therapy? J Antimicrob Chemother 2015; 70: 528-33.

47 Ulldemolins M, Soy D, Llaurado-Serra M et al. Meropenem population pharmacokinetics in critically ill patients with septic shock and continuous renal replacement therapy: influence of residual diuresis on dose requirements. Antimicrob Agents Chemother 2015; 59: 5520-8.

48 Thalhammer F, Hörl WH. Pharmacokinetics of meropenem in patients with renal failure and patients receiving renal replacement therapy. Clin Pharmacokinet 2000; 39: 271-9.

49 Tegeder I, Neumann F, Bremer F et al. Pharmacokinetics of meropenem in critically ill patients with acute renal failure undergoing continuous venovenous hemofiltration. Clin Pharmacol Ther 1999; 65: 50-7.

50 Ververs TF, van Dijk A, Vinks SA et al. Pharmacokinetics and dosing regimen of meropenem in critically ill patients receiving continuous venovenous hemofiltration. Crit Care Med 2000; 28: 3412-6.

51 Giles LJ, Jennings AC, Thomson AH et al. Pharmacokinetics of meropenem in intensive care unit patients receiving continuous veno-venous hemofiltration or hemodiafiltration. Crit Care Med 2000; 28: 632-7.

52 Kitzes-Cohen R, Farin D, Piva G et al. Pharmacokinetics and pharmacodynamics of meropenem in critically ill patients. Int J Antimicrob Agents 2002; 19: 105-10.

53 Krueger WA, Neeser G, Schuster H et al. Correlation of meropenem plasma levels with pharmacodynamic requirements in critically ill patients receiving continuous veno-venous hemofiltration. Chemotherapy 2003; 49: 280-6.

54 Novelli A, Adembri C, Livi P et al. Pharmacokinetic evaluation of meropenem and imipenem in critically ill patients with sepsis. Clin Pharmacokinet 2005; 44: 539-49.

55 Langgartner J, Vasold A, Gluck T et al. Pharmacokinetics of meropenem during intermittent and continuous intravenous application in patients treated by continuous renal replacement therapy. Intensive Care Med 2008; 34: 1091.

56 Roberts JA, Kirkpatrick CM, Roberts MS et al. Meropenem dosing in critically ill patients with sepsis and without renal dysfunction: intermittent bolus versus continuous administration? Monte Carlo dosing simulations and subcutaneous tissue distribution. J Antimicrob Chemother 2009; 64: 142-50.
57 Bilgrami I, Roberts JA, Wallis SC et al. Meropenem dosing in critically ill patients with sepsis receiving high-volume continuous venovenous hemofiltration. Antimicrob Agents Chemother 2010; 54: 2974-8.

58 Binder L, Schwörer H, Hoppe S et al. Pharmacokinetics of meropenem in critically ill patients with severe infections. Ther Drug Monit 2013; 35: 63-70.

59 Afshartous D, Bauer SR, Connor MJ et al. Pharmacokinetics and pharmacodynamics of imipenem and meropenem in critically ill patients treated with continuous venovenous hemodialysis. Am J Kidney Dis 2014; 63: $170-1$.

60 Mathew SK, Mathew BS, Neely MN et al. A nonparametric pharmacokinetic approach to determine the optimal dosing regimen for 30-minute and 3-hour meropenem infusions in critically ill patients. Ther Drug Monit 2016; 38: 593-9.

61 Valtonen M, Tiula E, Backman JT et al. Elimination of meropenem during continuous veno-venous haemofiltration and haemodiafiltration in patients with acute renal failure. J Antimicrob Chemother 2000; 45: 701-4.

62 Christensson BA, Nilsson-Ehle I, Hutchison M et al. Pharmacokinetics of meropenem in subjects with various degrees of renal impairment. Antimicrob Agents Chemother 1992; 36: 1532-7.

63 Kees MG, Minichmayr IK, Moritz S et al. Population pharmacokinetics of meropenem during continuous infusion in surgical ICU patients. J Clin Pharmacol 2016; 56: 307-15.

64 De Waele JJ, Carrette S, Carlier M et al. Therapeutic drug monitoringbased dose optimisation of piperacillin and meropenem: a randomised controlled trial. Intensive Care Med 2013; 40: 380-7.

65 Tröger U, Drust A, Martens-Lobenhoffer J et al. Decreased meropenem levels in Intensive Care Unit patients with augmented renal clearance: benefit of therapeutic drug monitoring. Int J Antimicrob Agents 2012; 40: 370-2.

66 Roberts JA, Ulldemolins M, Roberts MS et al. Therapeutic drug monitoring of $\beta$-lactams in critically ill patients: proof of concept. Int J Antimicrob Agents 2010; 36: 332-9.

67 Bragadottir G, Redfors B, Ricksten SE. Assessing glomerular filtration rate (GFR) in critically ill patients with acute kidney injury - true GFR versus urinary creatinine clearance and estimating equations. Crit Care 2013; 17: R108.

68 Baptista JP, Udy AA, Sousa E et al. A comparison of estimates of glomerular filtration in critically ill patients with augmented renal clearance. Crit Care 2011; 15: R139.

69 Brendel K, Dartois C, Comets E et al. Are population pharmacokinetic and/ or pharmacodynamic models adequately evaluated? A survey of the literature from 2002 to 2004. Clin Pharmacokinet 2007; 46: 221-34. 